\title{
Article \\ Identification of Novel Inhibitors of Type-I Mycobacterium Tuberculosis Fatty Acid Synthase Using Docking-Based Virtual Screening and Molecular Dynamics Simulation
}

\author{
Nidhi Singh ${ }^{1,2}$, Shi-Qing Mao ${ }^{1}$ and Wenjin $\mathrm{Li}^{1, *(\mathbb{C})}$ \\ 1 Institute for Advanced Study, Shenzhen University, Shenzhen 518060, China; \\ tanwar.nidhi7@gmail.com (N.S.); msq@szu.edu.cn (S.-Q.M.) \\ 2 College of Physics and Optoelectronic Engineering, Shenzhen University, Shenzhen 518060, China \\ * Correspondence: liwenjin@szu.edu.cn; Tel.: +86-755-26942336
}

Citation: Singh, N.; Mao, S.-Q.; Li, W. Identification of Novel Inhibitors of Type-I Mycobacterium Tuberculosis Fatty Acid Synthase Using Docking-Based Virtual Screening and Molecular Dynamics Simulation. Appl. Sci. 2021, 11, 6977. https:// doi.org/10.3390/app11156977

Academic Editor: Robert Jernigan

Received: 30 June 2021

Accepted: 27 July 2021

Published: 29 July 2021

Publisher's Note: MDPI stays neutral with regard to jurisdictional claims in published maps and institutional affiliations.

Copyright: () 2021 by the authors. Licensee MDPI, Basel, Switzerland. This article is an open access article distributed under the terms and conditions of the Creative Commons Attribution (CC BY) license (https:// creativecommons.org/licenses/by/ $4.0 /)$.

\begin{abstract}
Mycobacterial fatty acid synthase type-I (FAS-I) has an important role in the de novo synthesis of fatty acids, which constitute a major component of the cell wall. The essentiality of FAS-I in the survival and growth of mycobacterium makes it an attractive drug target. However, targeted inhibitors against Mycobacterial FAS-I have not been reported yet. Recently, the structure of FAS-I from Mycobacterium tuberculosis was solved. Therefore, in a quest to find potential inhibitors against FAS-I, molecular docking-based virtual screening and molecular dynamics simulation were done. Subsequently, molecular dynamic simulations based on binding free energy calculations were done to gain insight into the predicted binding mode of putative hits. The detailed analysis resulted in the selection of four putative inhibitors. For compounds BTB14738, RH00608, SPB02705, and CD01000, binding free energy was calculated as $-72.27 \pm 12.63,-68.06 \pm 11.80,-63.57 \pm 12.22$, and $-51.28 \pm 13.74 \mathrm{KJ} / \mathrm{mol}$, respectively. These compounds are proposed to be promising pioneer hits.
\end{abstract}

Keywords: fatty acid synthase; molecular docking; virtual screening; molecular dynamics simulations; MM/PBSA; binding free energy

\section{Introduction}

Tuberculosis (TB) is a leading health problem worldwide. According to the World Health Organization estimation, 10 million new cases were reported in 2018 alone, and 1.5 million people have died of it [1]. Tuberculosis is contagious and an airborne disease caused by Mycobacterium tuberculosis. The current drug regimen for the treatment of TB relies upon a six-month course of anti-microbial drugs [2]. The lengthy regimen leads to non-adherence and consequently the emergence and spread of drug-resistant strains. The rise of multi drug-resistant strains and co-occurrence with HIV also pose challenges in combating mycobacterium [2].

Mycobacterium has successfully evaded the host system since ancient times. Insight into the success story of Mycobacterium shows that virulence is largely attributed to its thick layer of mycolic acids, a major component of the cell wall [3-5]. It acts as an efficient barrier due to low permeability and fluidity and provides intrinsic resistance to anti-microbial drugs. The lipid biosynthesis in Mycobacterium is carried out by a combination of two enzymatic systems-FAS-I and FAS-II. Mycolic acids are long fatty acids and characterized by hydrophobic C54-C63 fatty acids with C22-C24 side chains in Mycobacterium [6]. The FAS-II system is comprised of four discrete enzymes, which work successively and repetitively to elongate the acyl chain, similar to the system found in prokaryotes and plants [7]. On the other hand, FAS-I is a multi-domain and multi-functional enzyme similar to fungi and higher eukaryotes [6,8]. It catalyses the de novo synthesis of fatty acids starting from acetyl-CoA and is capable of elongating fatty acids up to C24/26 [9]. The fatty acid chain is further elongated to meromycolate (C56) through the FAS-II system and later condensed 
with C26, resulting in the formation of mycolic acids [6,7]. Furthermore, fatty acid synthesis has been reported to be essential in mycobacteria $[10,11]$. The importance of fatty acid synthesis is also manifested by the use of drugs isoniazid, ethambutol, and pyrazinamide in the current drug regimen, which are inhibitors of mycolic acid biosynthesis [12]. Isoniazid and ethambutol targets enoyl reductase domain of the FAS-II system to inhibit mycolic acid synthesis and be used as first- and second-line drugs against TB. Pyrazinamide is being used as a first line drug and has a key role in shortening the drug regimen from nine to six months [13]. Moreover, analogs of pyrazinamide have been reported to target the FAS-I system of Mycobacterium [14,15]. The role of mycolic acids in forming the cell wall and its key role in growth and survival of mycobacterium makes the FAS system an attractive drug target. Recently the structure of mycobacterial FAS-I was elucidated by Nadav Elad et al. [16]. This has paved the way for structure based inhibitor identification against the mycobacterial FAS-I system.

The receptor-inhibitor design is the spirit of any drug design process and the information of receptor-ligand complex can be channelized through many ways. Amongst them, virtual screening is one of the most commonly used to discover novel scaffolds and lead compounds [17-19]. Molecular docking is a popular choice to carry out the virtual screening and has proved its mettle in hit identification and lead optimization. Molecular docking has been successfully implemented to screen large compound libraries against the drug targets and identification of mechanism of action of known active compounds [20-22]. Docking methods have been used to screen in-house as well as commercial libraries. For example, virtual screening was successfully employed for the identification of antibacterial inhibitors against NAD synthetase [23]. Docking-based virtual screening was done to identify novel inhibitors against leishmanial nucleoside diphosphate kinases [24]. In a recent study, docking-based screening was performed to identify potential inhibitors against isocitrate lyase of $\mathrm{Mtb}$ [25]. There are several other studies in which docking-based virtual screening has been successfully applied for the identification of novel inhibitors [26-30]. The Molecular Mechanics Poisson-Boltzman Surface Area (MM/PBSA) method is used to estimate binding affinity of protein-ligand complexes predicted by the molecular docking. The successful applications of MM/PBSA in virtual screening protocols has been reviewed by Giulio Poli et. al. [31].

To date, inhibitors of enoyl reductase domain of Mtb FAS-I have not been reported. Owing to the crucial role of FAS-I and available structural information, we were intrigued to search potential inhibitors against mycobacterial FAS-I. For this, molecular docking-based virtual screening protocol and molecular dynamics-based MM/PBSA calculations were implemented to identify putative hit compounds. The binding mode of active compounds has been proposed through molecular docking. The proposed inhibitors are pioneers and can serve as the basis for the design and optimization of new inhibitory compounds against TB.

\section{Materials and Methods}

\subsection{Ligand Library Preparation}

The commercial maybridge screening library [32] was selected to perform virtual screening. The selected maybridge collection consist of compounds which obey Lipinski's "rule of five"; hence, demonstrating good ADME parameters. In addition, screening collection represents over $87 \%$ pharmacophores in the world drug index. Therefore, the hits obtained can undergo further development. The screening library is available online and was downloaded from the website in sdf format. Firstly, the screening library was prepared for docking using the "surflex for searching" protocol of Sybyl 2.1 software. It follows the general clean-up and one least strained energy 3D conformer generation steps. The compounds collection obtained $(54,646)$ was saved and used for docking-based virtual screening. 


\subsection{Docking-Based Screening}

Surflex Docking: The Mtb FAS-I structure in complex with FMN was retrieved from the PDB database (PDBID: 6GJC). FAS-I is a large $\alpha 6$ subtype complex consisting of six long polypeptide chains. Each chain is 3069 amino acids long and contains seven catalytic domains. For primary screening and docking, the Surflex-Dock program of sybyl 2.1 was used in screen mode [33]. For the receptor preparation step, only chain A was retained, while the other chains and water molecules were removed. The FMN molecule was also retained as it is found tightly bound to FAS-I. In addition, hydrogen atoms were added, and atom types and AMBER charges were assigned to protein atoms. Ligand NADPH was extracted from the structure of FAS-I of thermomyces lanuginosus (PDB:4V59), which is homologous to mycobacterial FAS-I. Ligand-based protomol was generated using NADPH, keeping the threshold 0.5 and bloat set to default. The molecular docking was done with default settings. In the next step, re-ranking of high scoring hits was done using the Geom-X mode. The spin density for search is higher in Geom-X mode and set to the value of nine, while in screen mode it is three. Therefore, accuracy in ranking the hits on the basis of docking score is enhanced as the search becomes denser. Surflex is based on the Hammerhead procedure for docking the flexible ligands into the binding site of the receptor. It is based upon the generation of ligand fragments and their alignment onto the identified probes; the remaining fragments of ligands were then docked. The scoring function is empirical and derived through a weighted sum of non-linear functions of protein-ligand atomic Van der Waals surface distances. Hydrophobic, entropic, polar, solvation, repulsive, and crash terms are included in the scoring function. The score predicts binding affinity in $-\log 10(\mathrm{Kd})$ units.

\subsection{Molecular Dynamics Simulation}

To assess the suitability of the selected hits after docking score filter in terms of stability of protein-ligand interactions, molecular dynamics simulations were carried out using GROMACS 5.0 software [34]. The topology for ligands was generated through the cGenff server $[35,36]$. The CHARMM36 force field was applied to the protein-ligand systems. The system was kept in a cubic box and placed $10 \AA$ from the box edge. The TIP3P water model was used for protein-ligand complexes. The whole system was neutralized by adding appropriate ions and energy minimization was done using the steepest descent algorithm. In the next step, energy minimized systems were subjected to NVT and NPT equilibration phases for $100 \mathrm{ps}$ each. Isotropic pressure coupling was performed using the Parrinello-Rahman method, keeping the pressure coupling time at 2 ps and isothermal compressibility $4.5 \times 10^{-5} \mathrm{bar}^{-1}$. Electrostatic interactions were treated with Particle Mesh Ewald method [37]. Coulomb and Van der Waals interactions were truncated at $1 \mathrm{~nm}$. The systems were subjected to production run for ten ns each and at every ten ps, conformations were saved. The gromacs rms utilities were employed to calculate root mean square deviation (r.m.s.d) of ligands. The GRACE program was used to plot the graphs [38]. The molecular dynamics simulation was used to calculate protein-ligand interaction energy based upon the MM/PBSA method.

\subsection{MM/PBSA-Based Protein-Ligand Interaction Energy Calculation}

In order to calculate the binding energy for predicted complexes, the MM/PBSA method was applied. The simulation-based end point methods, such as molecular mechanics with Poisson-Boltzmann (MM/PBSA) and molecular mechanics with generalized Born and surface area (MM-GBSA) due to their computational efficiency [39-42]. For all complexes, binding free energy calculations was carried out using the g_mmpbsa tool [40]. The binding free energy is given by:

$$
\begin{gathered}
\Delta G_{\text {bind }}=\left\langle\Delta E_{M M}\right\rangle-T \Delta S+\left\langle\Delta G_{\text {solvation }}\right\rangle \\
\Delta E_{M M}=\Delta E_{\text {bonded }}+\Delta E_{\text {vdW }}+\Delta E_{\text {elec }}
\end{gathered}
$$




$$
\Delta G_{\text {solvation }}=\Delta G_{\text {polar }}+\Delta G_{\text {nonpolar }}
$$

Here, $\Delta E_{M M}$ represents the energy of bonded and non-bonded terms and is calculated on the basis of molecular mechanics force-field parameters. In addition, in the single trajectory approach, the protein ligand conformation in bound and unbound form is identical and therefore is assumed to be zero [43]. The solvation free energy term includes polar and non-polar terms. The polar solvation energy is solved using the Poisson-Boltzmann equation [44] while non-polar solvation energy is calculated by attractive and repulsive forces between the solute and solvent, generated through cavity formation and Van der Waals interactions [45,46]. For the current study, MM/PBSA calculations were done on the last $5 \mathrm{~ns}$ segment of the trajectory. For each system, 100 snapshots were extracted at the interval of $50 \mathrm{ps}$ along the trajectory.

\section{Results}

\subsection{Structural Model of NADPH-Bound Mtb FAS-I}

Mtb FAS-I is a large $\alpha 6$ subtype barrel-shaped complex consisting of six long polypeptide chains ( $\alpha$ chains). Each $\alpha$ chain is 3069 amino acids long and comprised of seven catalytic domains [16]. The overall architecture depicts the whole complex as a central wheel capped by domes on each side. The seven catalytic domains are namely acetyltransferase, enoyl reductase (ER), dehydratase, malonyl transacylase, ketoacyl reductase, ketoacyl synthase, and acyl carrier protein. The Mtb FAS-I was found to be similar to fungal FAS which is a homolog that retains the barrel shape complex [37]. The comparison of catalytic clefts between mycobacterial and fungal domains is given in detail [16]. Furthermore, the crystal structure of fungal FAS-I has been reported in complex with NADP+ and FMN (PDB:4V59). The structural comparison revealed that the enoyl reductase domain of Mtb has a wider catalytic cleft and FMN is more exposed due to local amino acid composition. The ER domain is involved in the catalysis of the last step of fatty acid elongation cycle through FMN-dependent reduction of enoyl-ACP intermediate to saturated acyl-ACP. The ER is embedded in the FAS-I complex so that it allows easy access of NADPH to the binding site from outside of the FAS-I complex, while the catalytic centre is accessible from the inside of the reaction chamber. A two-step ping-pong mechanism had been proposed for catalytic mechanism of the ER of fungal FAS-I [47]. Moreover, analogs of pyrazinamide have been reported to be competitive inhibitors of NADPH binding to Mtb FAS-I [14]. Hence, we were intrigued to identify putative inhibitors of Mtb FAS-I. The availability of the Mtb FAS-I structure paved the way for docking-based screening. Taking in consideration the close homology with fungal FAS-I, NADPH was extracted from fungal FAS-I and docked to the binding site of Mtb FAS-I (Figure 1a). The residues involved in the binding site of NADPH were studied and compared (Table 1) to the NADPH binding site in fungal FAS-I. The residues were found to be conserved and thus indicates the suitability of NADPH binding. The residues Tyr636, Lys1026, and pro1027 hold adenosine moeity; Asp 1045 interacts with pyrophophate part, while His 751 acts as a catalytic residue in fungal FAS-I. Similarly, the corresponding residues in Mtb FAS-I have been tabulated (Table 1). Notably, the residue His584 in Mtb seems to act as a catalytic residue and can play an important role in the function of the enoyl reductase domain. 


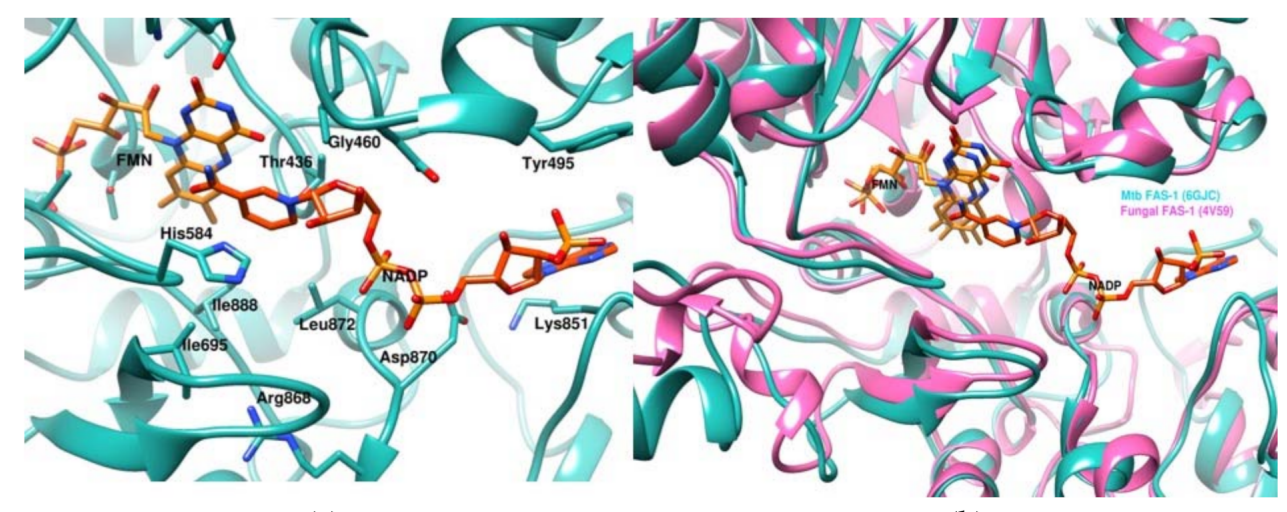

(a)

(b)

Figure 1. (a) Mtb FAS-I shown in cyan color with bound FMN and docked NADP (b) The enoyl reductase domain of Mtb FAS-I (cyan color, PDB:6GJC) superimposed onto Thermomyces lanuginosus FAS-I (pink color, PDB:4V59).

Table 1. The residue comparison for the NADPH binding site of enoyl reductase between fungal and Mtb FAS-I.

\begin{tabular}{ll}
\hline $\begin{array}{l}\text { NADPH Binding Site Residues from } \\
\text { Thermomyces Lanuginosus (PDB Code: } \\
\text { 4V59) }\end{array}$ & $\begin{array}{l}\text { NADPH Binding Site Residues from Mtb } \\
\text { (PDB Code: 6GJC) Obtained by Docking }\end{array}$ \\
\hline Tyr636 & Tyr495 \\
\hline Asp668 & - \\
\hline Asp952 & - \\
\hline Lys1026 & Lys851 \\
\hline Pro1027 & Pro852 \\
\hline Asp1045 & Asp870 \\
\hline Ser1046 & Ser871 \\
\hline Lys1044 & Ser869 \\
\hline Leu1047 & Leu872 \\
\hline Thr609 & Thr436 \\
\hline Ile663 & Leu490 \\
\hline Gly749 & Gly582 \\
\hline Gly750 & Gly583 \\
\hline His751 & His584 \\
\hline Glu863 & - \\
\hline
\end{tabular}

\subsection{Docking-Based Screening}

To discover novel Mtb FAS-I inhibitors, the cryo-EM structure of FAS-I in complex with FMN (PDB ID: 6GJC) was used for molecular docking-based virtual screening utilizing the Surflex-dock module of the Sybyl 2.1 software. The NADP binding pocket was used for performing docking-based screening, comprised of residues Met435, Thr436, Pro437, ValL440, Ala458, Gly460, GLY583, His584, His585, Ala693, Asp694, Ile695, Pro852, Arg868, Ser869, Asp870, Ser871, Leu872, Trp873, Gln874, and the FMN molecule. To address accuracy and efficiency, we carried out the screening protocol in a hierarchical strategy summarized in a work-flow diagram (Figure 2). 
FAS-I structure $(\mathrm{PDB} I D=6 \mathrm{G} J \mathrm{C})$

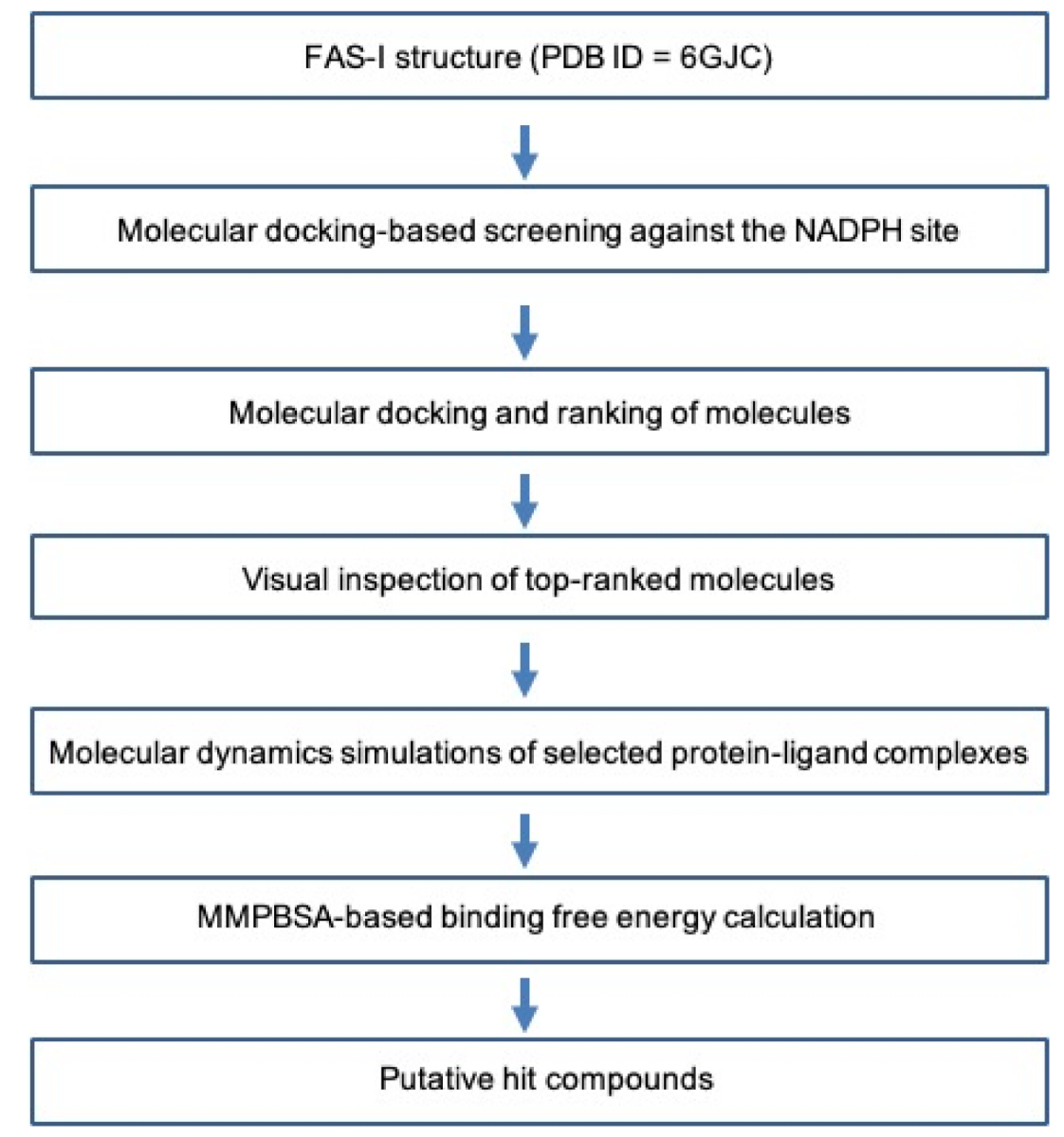

Figure 2. The work plan for molecular docking-based virtual screening.

Primary screening: The Maybridge screening library consisting of 54,646 molecules was docked using Surflex-dock into the active site of Mtb FAS-I. The top scoring molecules with a score equal to or higher than the score (8.0) for the binding site were considered for the next step. The choice of cut-off value in this study was guided by reproduction of docking pose of phenylimidazole derivative inhibitor enoyl-ACP reductase (FabK) from Streptococcus pneumoniae, which is competitive inhibitor of NADPH (PDB:2Z6J). This cut-off resulted in 528 molecules, which were docked again using Surflex-GeomX mode for re-ranking and to improve pose accuracy. Subsequently, the top 150 molecules were inspected visually for favorable interactions.

Visual inspection: The hits from GeomX were inspected visually for their binding mode(s) for further selection. The following criteria were considered: (1) $\pi-\pi$ stacking interaction between the ligand and the FMN molecule; (2) the interaction with residues His584 and Thr436; (3) the formation of hydrogen bonds and other hydrophobic interactions; and (4) the stability in docked pose and fitness of molecule in the binding site. This step was primarily used to enhance specificity and eliminate the compounds having higher score due to interactions with other residues. Based on these criteria, a total of nine molecules were selected for subsequent molecular dynamics simulations. The structures of these compounds are shown in Figure 3. 

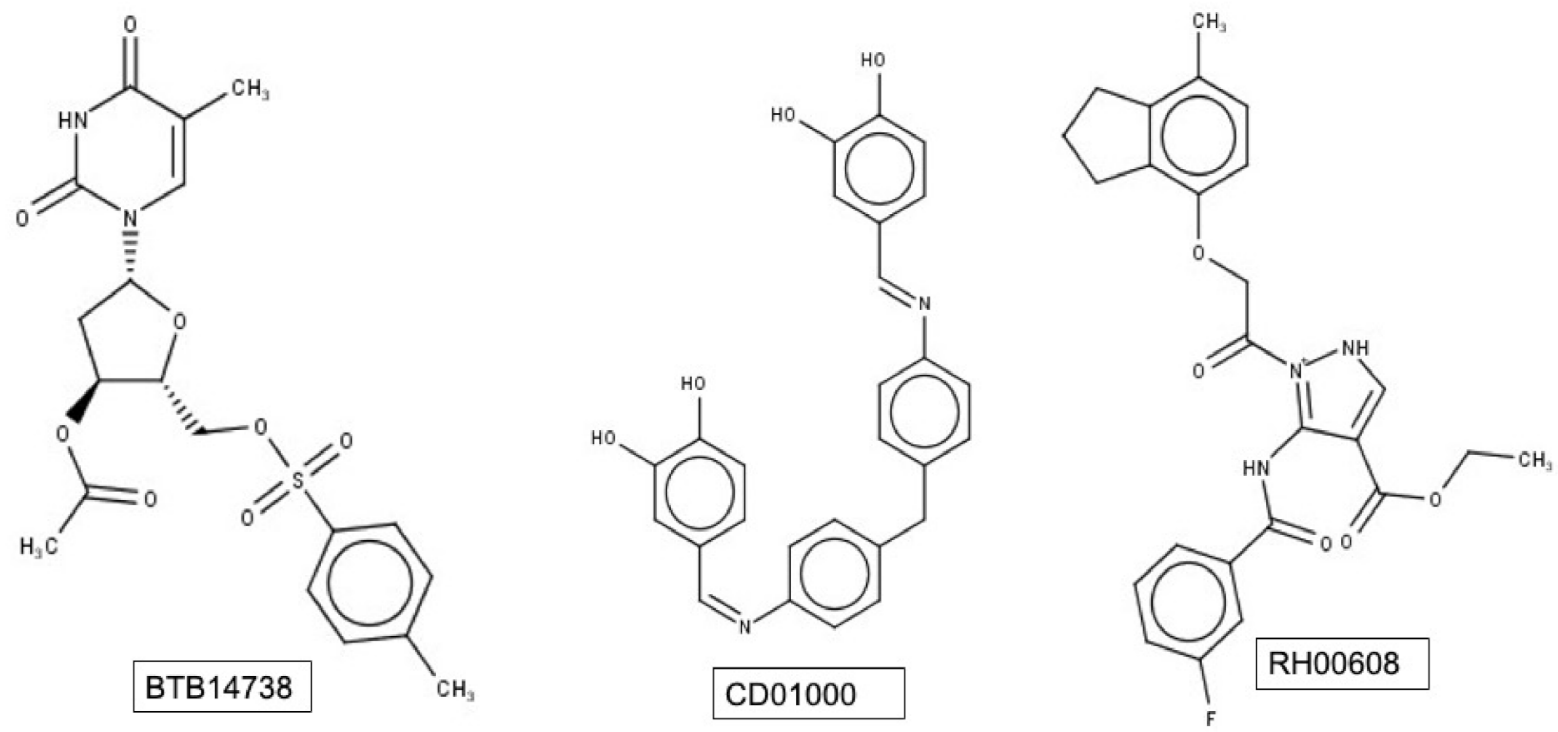

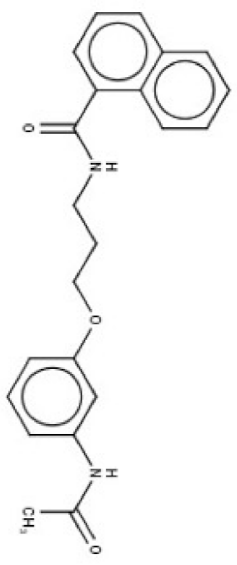

BTB14516<smiles>COC(=O)Cc1c(C)ncnc1OCC(=O)Nc1ccc2c(c1)OCCO2</smiles>

HTS07760

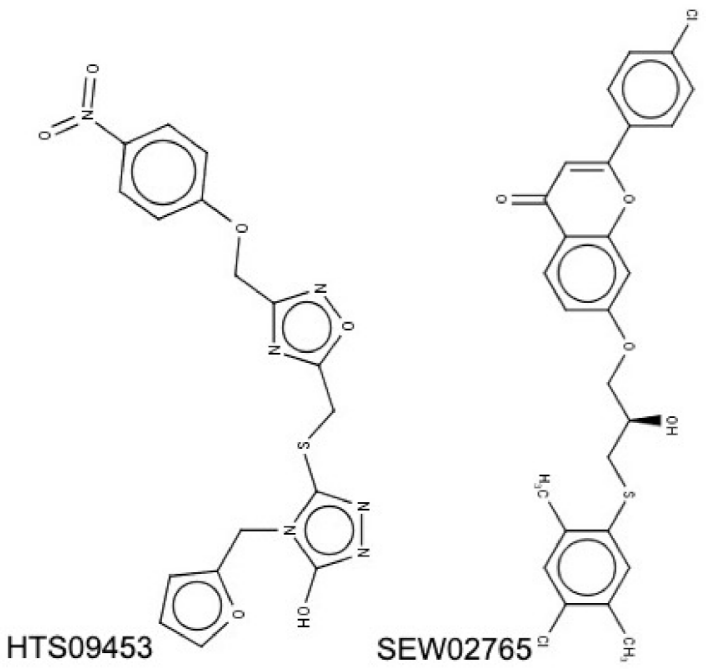

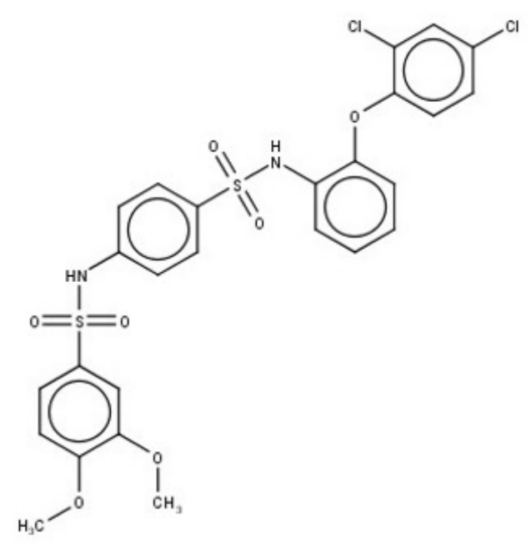

RJF01717

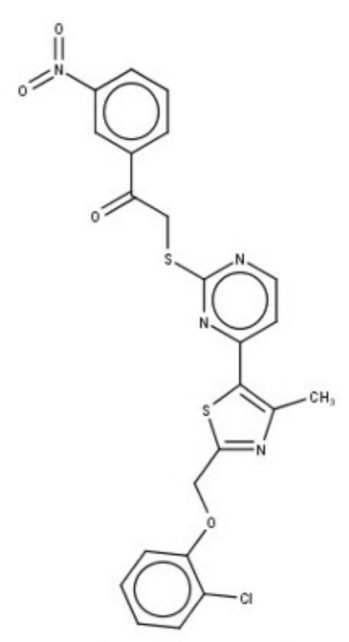

SPB02705

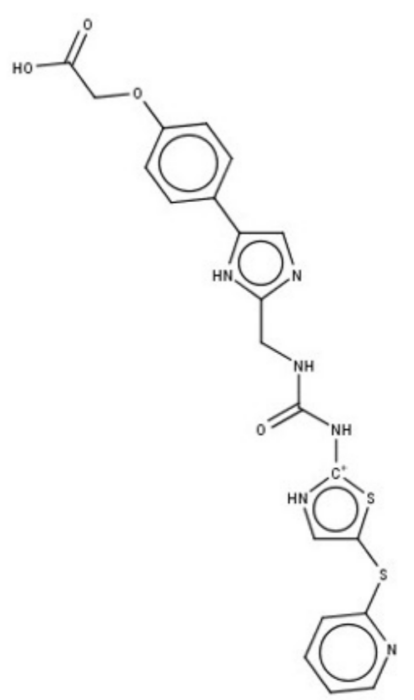

Phenylimidazole inhibitor (PDB:2Z6J)

Figure 3. The structures of nine selected compounds after docking-based screening are shown along with the inhibitor of $S$. pneumoniae Enoyl-Acyl Carrier Protein Reductase (FabK). The labels of four putative inhibitors are highlighted in boxes. 


\subsection{Molecular Docking and Proposed Mode of Binding of Putative Hits}

The predicted binding mode of compounds selected on the basis of molecular docking and visual inspection are discussed in this section. The detailed 2D interaction plots for all the complexes are given in detail (Figure S1), while the 3D interaction plots for proteinligand complexes are shown in Figure 4. The compound BTB14738 showed hydrogen bonding with residues Thr436 and Arg868 and strong $\pi-\pi$ stacking with FMN molecule. The residues Leu872 and Ile695 are involved in hydrophobic interaction, while the sulfur atom can be involved in $\pi$-sulfur interaction with residue His584 (Figure 4a). The compound BTB14516 showed hydrogen bonds with the residues Thr436, Gly460, and His584 and $\pi-\pi$ stacking with the FMN molecule (Figure $4 \mathrm{~b}$ ). The compound CD01000 showed hydrogen bonds with the residues Arg868, Gln690, and Lys550 and $\pi-\pi$ stacking with the FMN molecule (Figure 4c). The compound SEW02765 showed extensive interactions in the form of hydrogen bonds with the residues Thr436 and Arg868 and $\pi$-sulfur with His584. The residues Leu490, Ala524, Ile888, Ile695, and Leu872 provided hydrophobic contacts (Figure 4d). The compound HTS07760 showed favorable interactions in the form of hydrogen bonds with the residues Thr436, His584, and Arg868 and $\pi-\pi$ stacking with the FMN molecule (Figure 4e). The compound HTS09453 showed hydrogen bonds with residues His584, Thr436, Arg868, and Ser871 and $\pi-\pi$ stacking with the FMN molecule (Figure 4f). The next compound RH00608 showed hydrogen bond with the residues Thr436, His584, Arg868, and halogen bond with the residue Asp870 and $\pi-\pi$ interaction with FMN. It is stabilized through various hydrophobic contacts to Ala524, Ala581, Ile695, Ile888, and Leu872 (Figure 4g). The compound RJF01717 showed extensive hydrogen bonds with residues His584, Thr436, Ser523, Gln690, Ser871 and Arg868 and retaining $\pi-\pi$ stacking with FMN (Figure $4 \mathrm{~h}$ ). The compound SPB02705 showed $\pi-\pi$ stacking with residue His584 and the FMN molecule through two aromatic rings and hydrogen bonds with residues His584 and Arg868 (Figure 4i). In brief, the compounds showed hydrogen bond formation mainly with the residues Thr436, His584, and Arg868. Notably His584 is the catalytic residue and is found to be conserved. The hydrophobic contacts are driven by Ala524, Leu490, Leu872, Ile695, and Ile888. The strong $\pi-\pi$ interactions are also predicted between the ligand and FMN molecule or residue His584. Thus, favorable interactions between protein-ligand complexes were predicted.

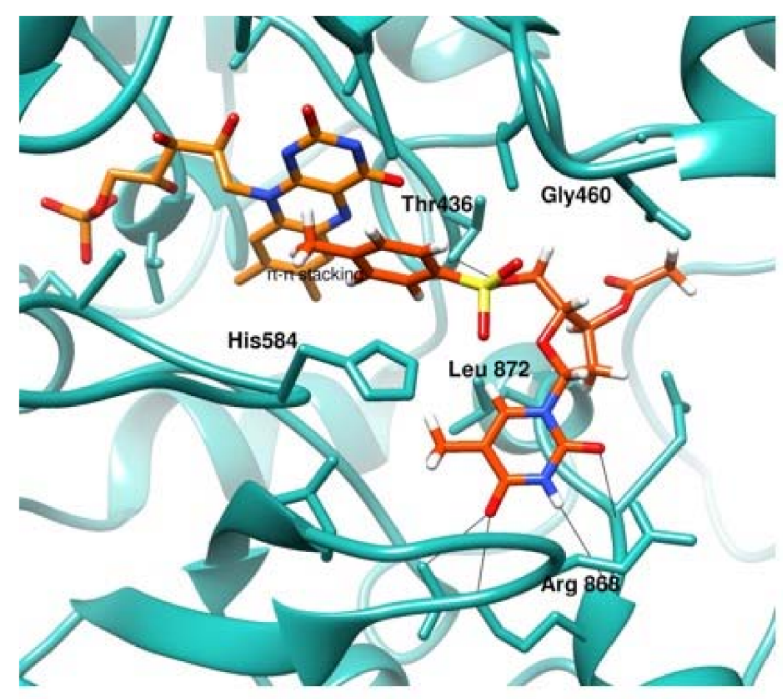

(a)

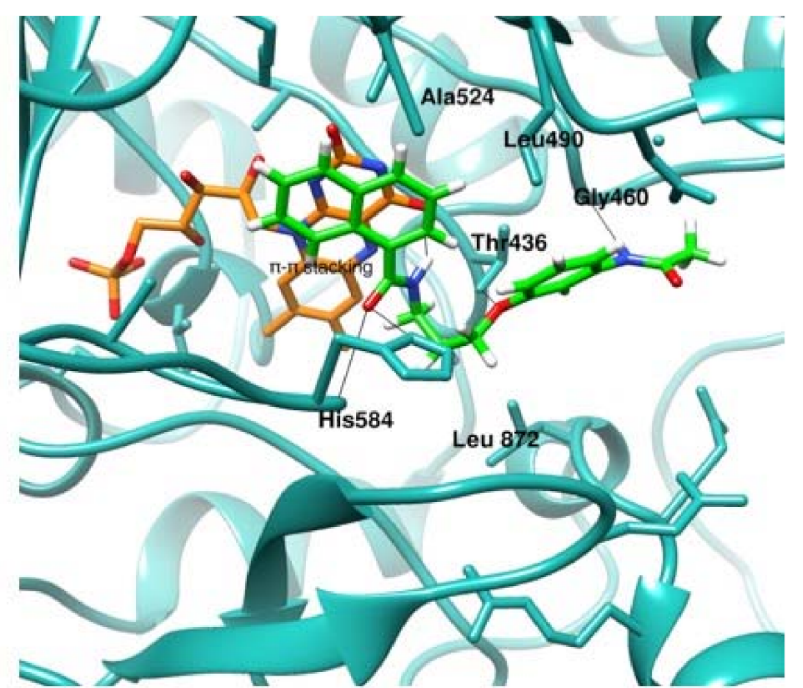

(b)

Figure 4. Cont. 


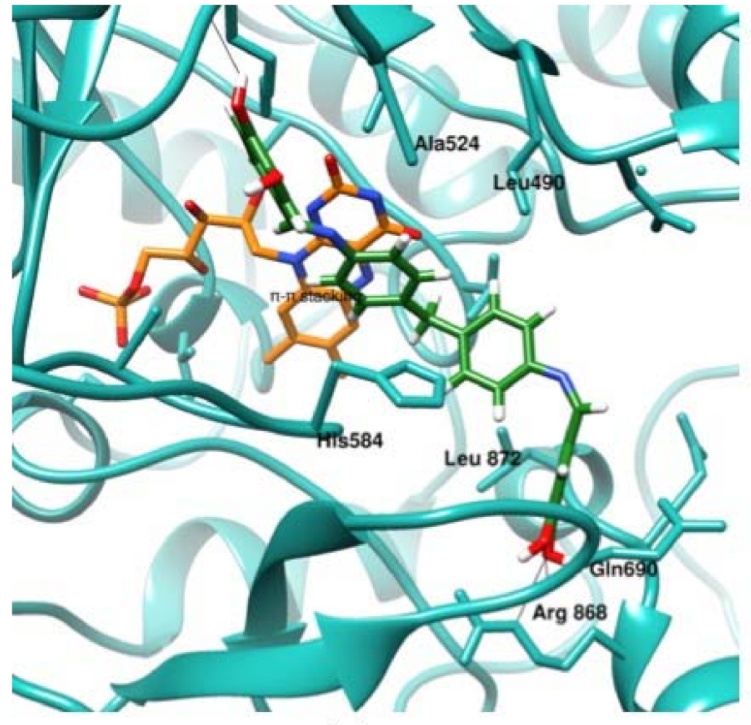

(i)

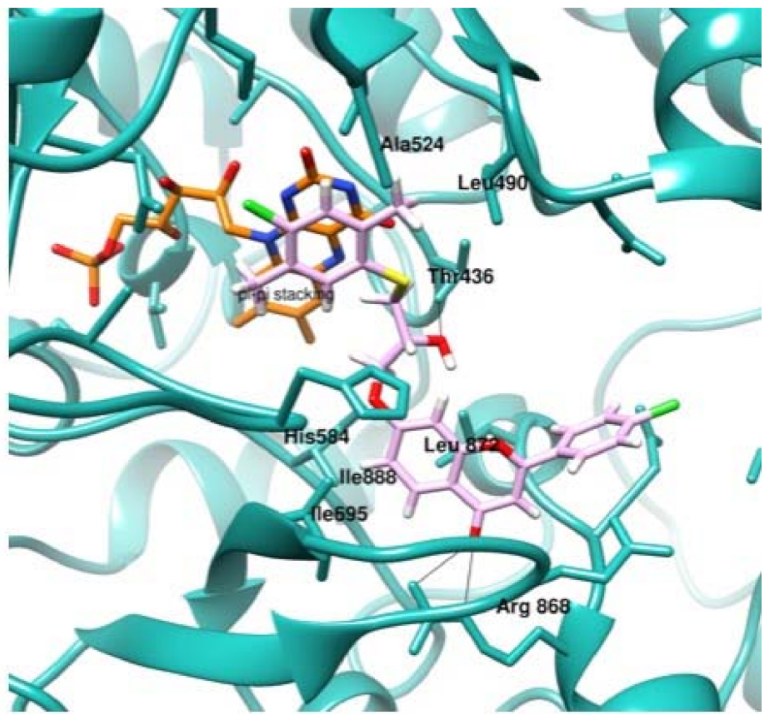

(i)

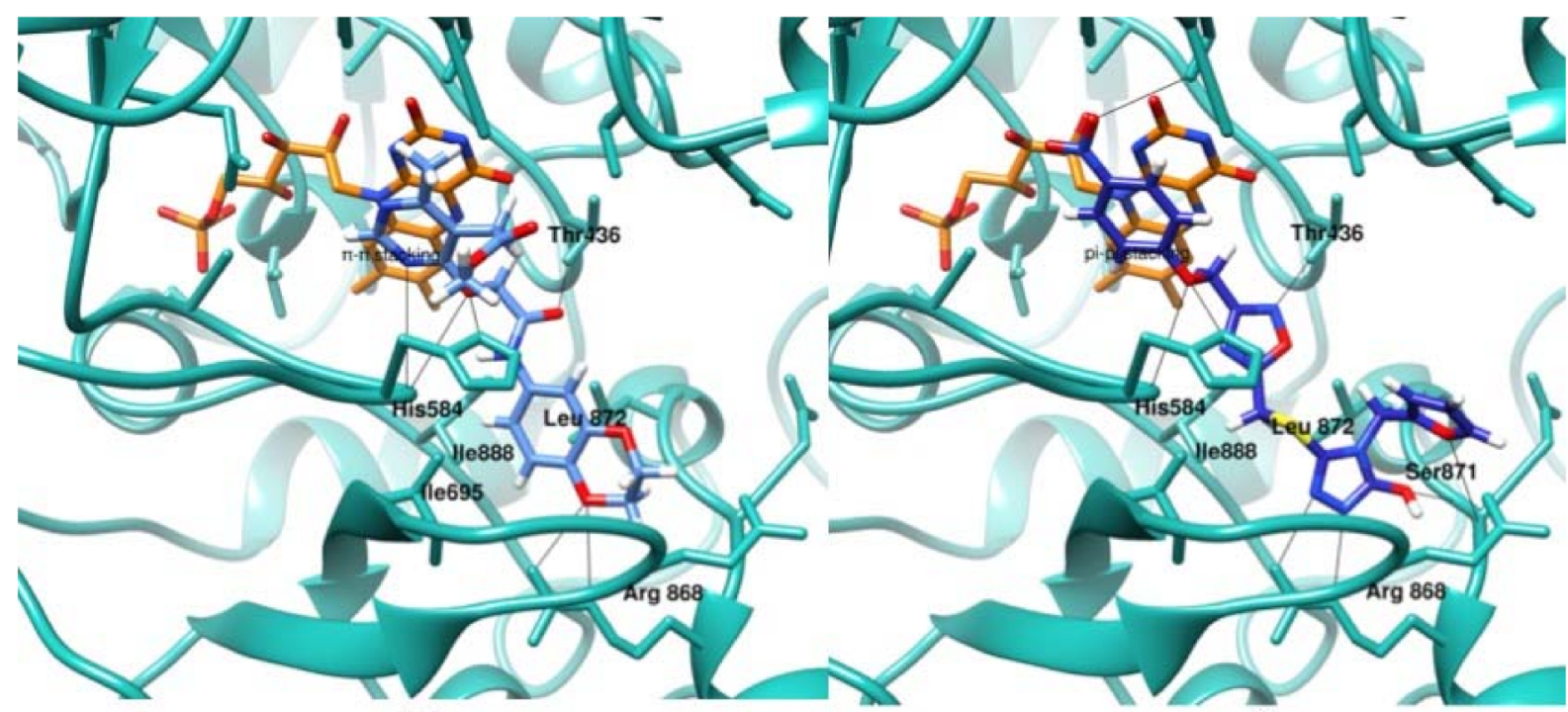

(e)

(f)

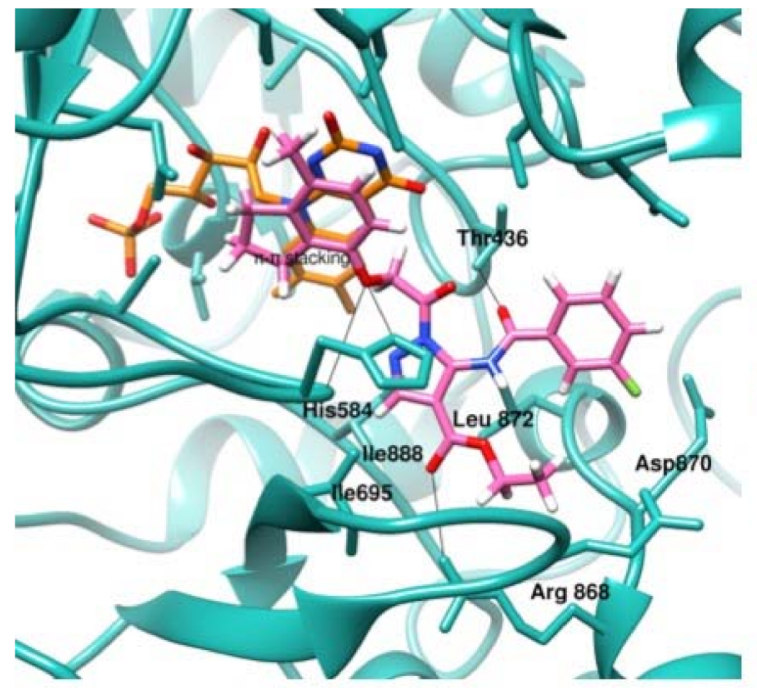

(g)
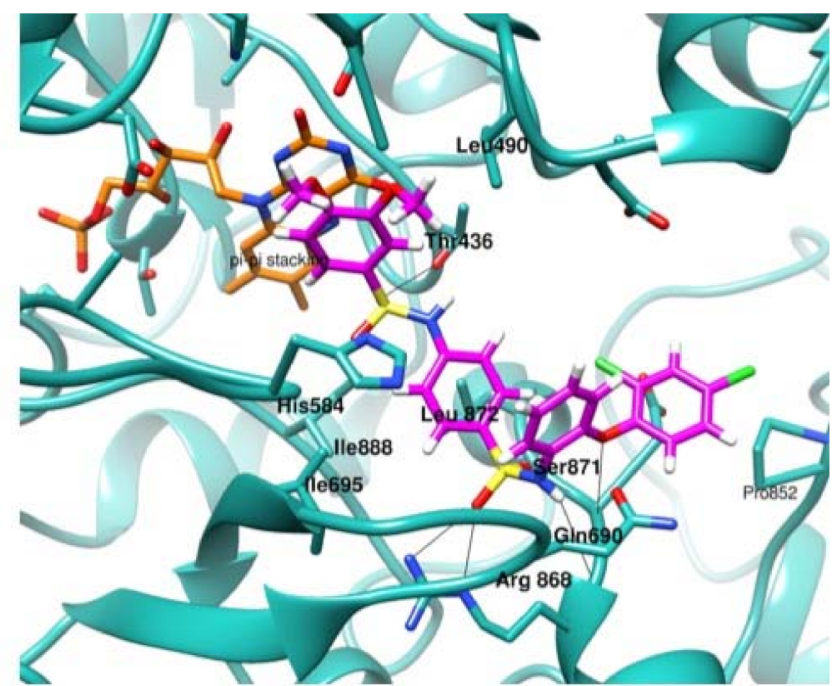

(h)

Figure 4. Cont. 


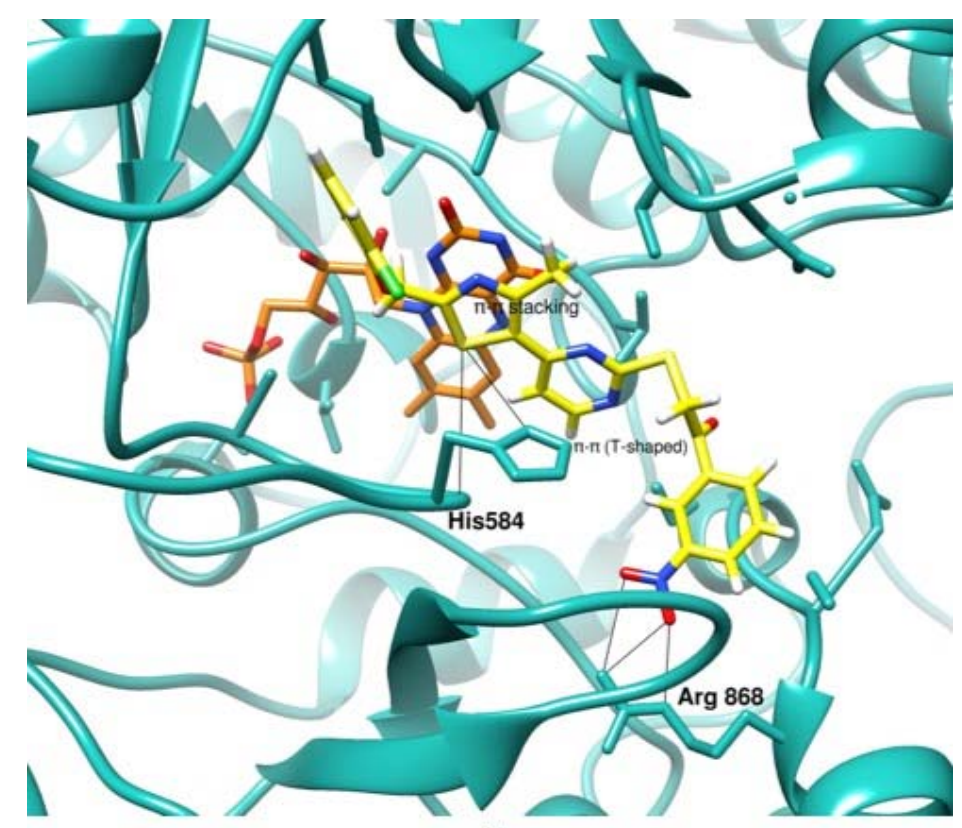

(i)

Figure 4. The 3D interaction plots for selected protein-ligand complexes (a) BTB14738, (b) BTB14516, (c) CD01000, (d) SEW02765, (e) HTS 07760, (f) HTS09453, (g) RH00608, (h) RJF01717, (i) SPB02705.

\subsection{Molecular Dynamics Simulation}

In order to obtain a better insight as well as to assess the stability of the binding mode of molecules, we conducted $10 \mathrm{~ns}$ long molecular dynamic simulations for all the nine proteins-ligand complexes selected after the visual inspection step. The poses selected from the Geom X docking experiment were used as the starting poses for simulation studies. Keeping in consideration the large size of FAS-I, simulation was done for the enoyl reductase domain (amino acid residue 394-1107). The NADPH binding site of the ER domain is far away from the interaction sites between the ER domain and other neighbouring domains; it is thus unlikely that the neighbouring domains contribute to the interaction between the ER domain and the proposed inhibitors. The structure of the ER domain is close to the one in the FAS-I complex, as indicated by the small RMSD in all simulations. In the next step, the resultant trajectory was analyzed for assessing the stability of the predicted protein-ligand complexes. The r.m.s.d of the ligand was calculated using g_rms command in GROMACS. The r.m.s.d for ligands was plotted for all complexes from the end of equilibration phase and was found to be low, indicating the stability of ligand poses. The average r.m.s.d of ligand atoms was calculated to $0.24,0.18,0.12,0.15$, $0.21,0.11,0.16,0.20$, and $0.21 \mathrm{~nm}$ for BTB14516, BTB14738, CD01000, HTS07760, HTS09453, RH00608, RJF01717, SEW02765, and SPB02705, respectively (Figure 5). The FMN molecule was found to be very stable with average r.m.s.d calculated in the range of $0.05-0.11 \mathrm{~nm}$ (Figure S2). The average r.m.s.d for backbone atoms of complexes was calculated in the range of $0.19-0.26 \mathrm{~nm}$ (Figure S2). Overall, the protein-ligand complexes were found to be significantly stable. Subsequently, the last five ns MD trajectory was used for performing $\mathrm{MM} / \mathrm{PBSA}-\mathrm{based}$ binding free energy calculations and is discussed in the next section. 
RMSD

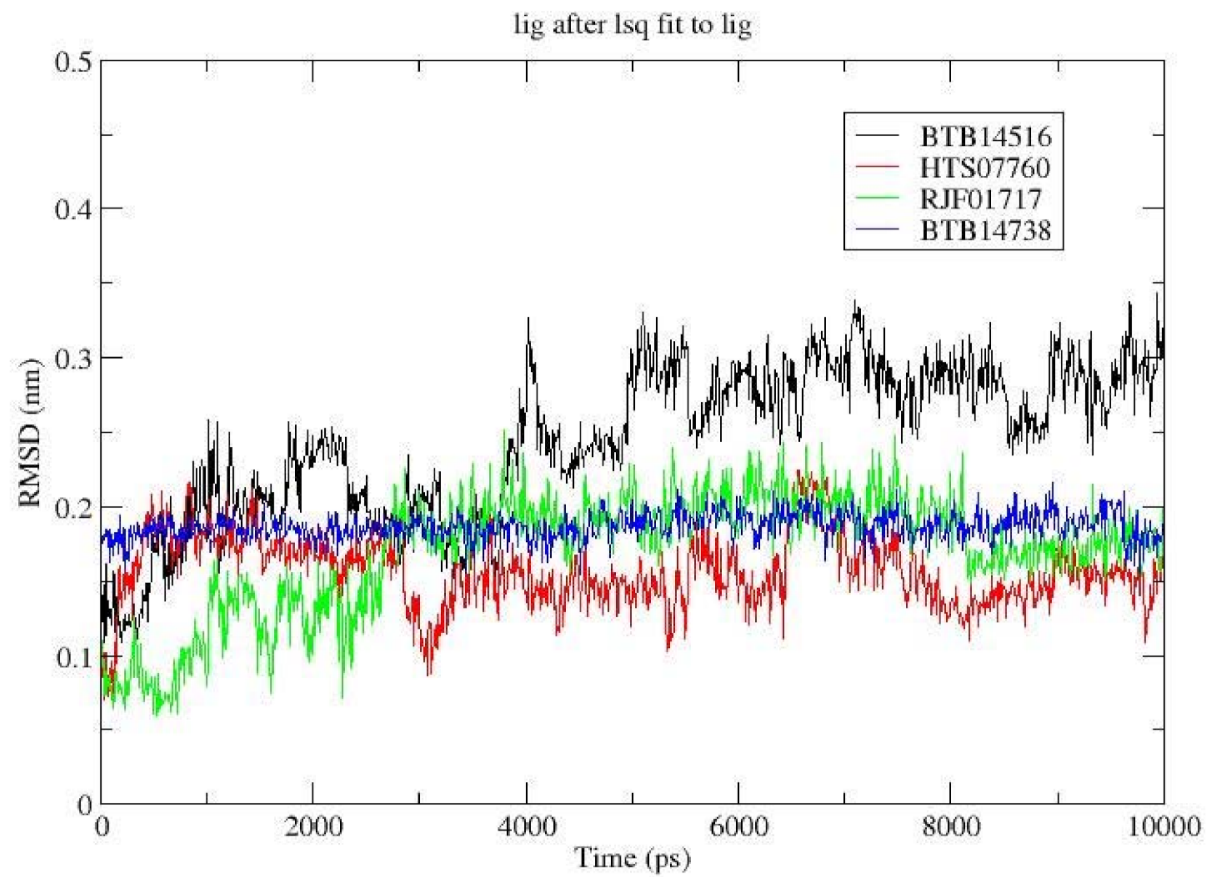

(A)

\section{RMSD}

lig after Isq fit to lig

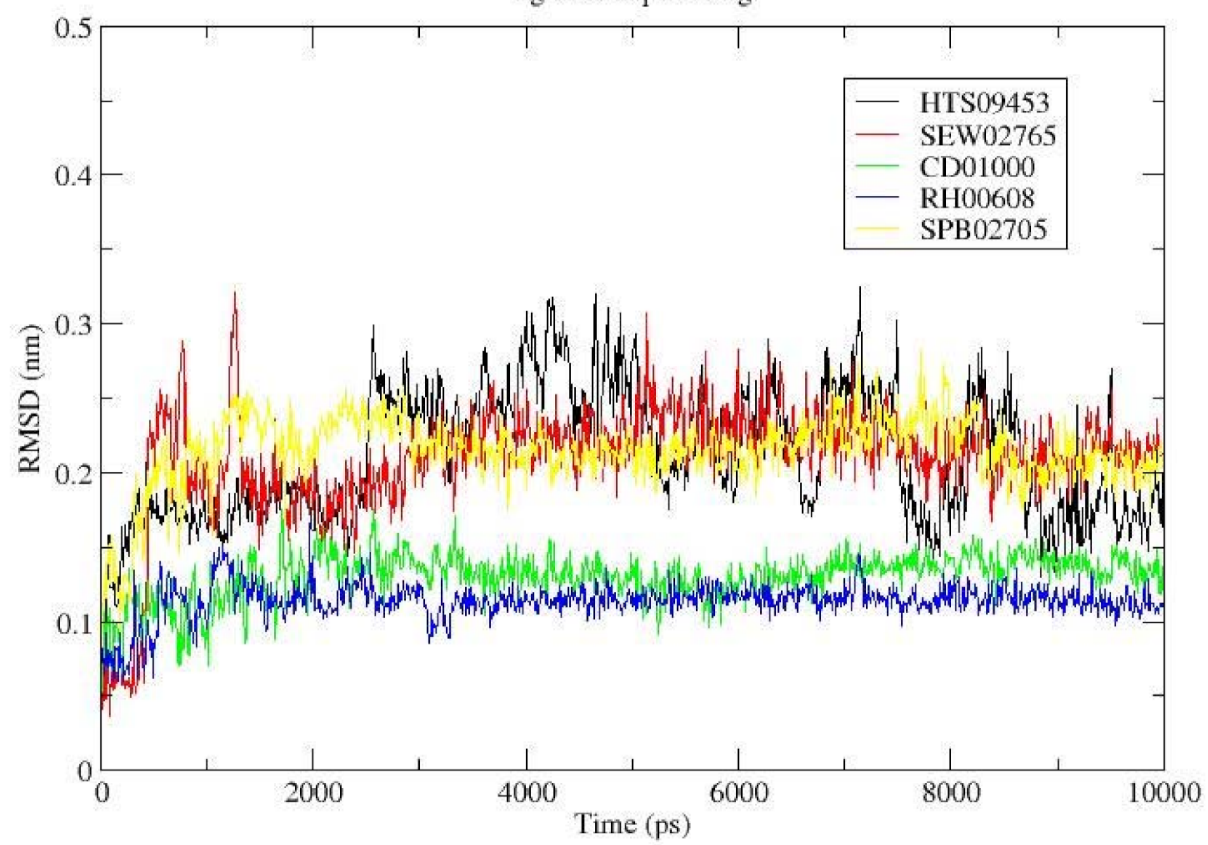

(B)

Figure 5. The r.m.s.d plots for ligand are given for (A) BTB14516, HTS07760, RJF01717, BTB14738 (B) CD01000, HTS09453, RH00608, SPB02705, and SEW02765. 


\subsection{MM/PBSA-Based Interaction Energy Calculation}

The computational efficiency and accuracy of simulation-based end point methods such as molecular mechanics with Poisson-Boltzmann (MM/PBSA) and molecular mechanics with generalized Born and surface area (MM/GBSA) provides a reliable choice for binding free energy calculations [42]. These methods are based upon sampling of the final state of the system and the solvent is treated implicitly, thus reducing the computational time. However, these methods possess limitations regarding the estimation of conformational and solvation entropies [48]. In order to prioritize and re-rank the compounds, $\mathrm{MM} /$ PBSA-based binding free energy was calculated for all the nine complexes. For each system, 100 snapshots were fetched at the interval of $50 \mathrm{ps}$ along the last five ns trajectory. All the compounds showed favorable binding free energy values. The compound BTB14738 was predicted to show the highest binding free energy value of $-72.27 \pm 12.63 \mathrm{KJ} / \mathrm{mol}$. The other compounds RH00608, SPB02705, CD01000, and HTS07760 are also predicted to show high binding free energy values of $-68.06 \pm 11.80,-63.57 \pm 12.22,-51.28 \pm 13.74$, and $-53.17 \pm 12.68 \mathrm{KJ} / \mathrm{mol}$. However, the compound SEW02765 is predicted to show the lowest binding free energy value. The binding free energies of protein-ligand complexes is summarized in Table 2. The compounds were ranked upon the basis of predicted binding free energy. The selected compounds showed high predicted binding free energy, indicating better binding and potentially better inhibitory efficiency. The MM/PBSA approach has been reported to be applied reliably for re-scoring the protein-ligand complexes predicted by molecular docking. Thus, it helps in boosting the virtual screening hit rates [31,49]. The accuracy of the method is limited by the lack of conformational entropy, missing effect of water molecules in the binding site and details in the method, such as dielectric constant, continuum-solvation method, and charges [50]. Therefore, this method has been applied to systems with a varying degree of success. Nevertheless, the method has been useful to corroborate the docking results and understand the observed affinities [51,52].

Table 2. The predicted binding free energy and molecular docking score for selected protein-ligand complexes is listed.

\begin{tabular}{cccc}
\hline Serial Number & Compound ID & $\begin{array}{c}\text { Predicted Binding } \\
\text { Free Energy (KJ/mol) }\end{array}$ & $\begin{array}{c}\text { Molecular Docking } \\
\text { Score }\end{array}$ \\
\hline 1. & BTB14738 & $-72.27 \pm 12.63$ & 9.55 \\
\hline 2. & RH00608 & $-68.06 \pm 11.80$ & 10.80 \\
\hline 3. & SPB02705 & $-63.57 \pm 12.22$ & 9.30 \\
\hline 4. & HTS07760 & $-53.17 \pm 12.68$ & 9.28 \\
\hline 5. & CD01000 & $-51.28 \pm 13.74$ & 10.41 \\
\hline 6. & BTB14516 & $-48.91 \pm 11.37$ & 10.01 \\
\hline 7. & RJF01717 & $-44.82 \pm 15.77$ & 10.18 \\
\hline 8. & HTS09453 & $-43.30 \pm 14.27$ & 10.46 \\
\hline 9. & SEW02765 & $-16.44 \pm 13.22$ & 9.75 \\
\hline
\end{tabular}

Taking into consideration the predicted binding free energy values, stability of the bound ligand along with molecular docking score, four compounds (BTB14738, SPB02705, RH00608, and CD01000) were selected as potential hits (Figure 3). For compound BTB14738, the highest binding free energy of $-72.27 \pm 12.63$ was estimated. The ligand r.m.s.d was calculated to be $0.11 \mathrm{~nm}$, indicating high stability. Similarly, the compounds RH00608, SPB02705, and CD01000 also showed high favorable binding free energy values and stable ligand binding. Thus, molecular docking-based virtual screening together with molecular dynamics and the MM/PBSA method has resulted in the identification of pioneer putative hits against Mtb FAS-I. 


\subsection{Discussion}

Firstly, the MM/PBSA result for the selected compounds BTB14738, RH00608, SPB02705, and CD01000 is given in detail in Table 3. It has been shown that Van der Waals interaction contributed more towards the favorable binding of compounds while the contribution of electrostatic interaction was estimated to be lower. Hence, Van der Waals forces are an important form of interaction between the ligand and the protein.

Table 3. The MM/PBSA results for the selected putative hits. All energies are in unit of $\mathrm{KJ} / \mathrm{mol}$.

\begin{tabular}{cccccc}
\hline Compound Code & $\begin{array}{c}\text { Van der Waals } \\
\text { Energy }\end{array}$ & $\begin{array}{c}\text { Electrostatic } \\
\text { Energy }\end{array}$ & $\begin{array}{c}\text { Polar Solvation } \\
\text { Energy }\end{array}$ & SASA Energy & $\begin{array}{c}\text { Binding Free } \\
\text { Energy }\end{array}$ \\
\hline BTB14738 & $-165.92 \pm 11.998$ & $-33.77 \pm 6.45$ & $146.82 \pm 13.80$ & $-19.39 \pm 0.97$ & $-72.27 \pm 12.63$ \\
\hline RH00608 & $-219.005 \pm 10.53$ & $-14.61 \pm 6.551$ & $190.10 \pm 10.54$ & $-24.55 \pm 1.22$ & $-68.06 \pm 11.80$ \\
\hline SPB02705 & $-183.88 \pm 16.99$ & $-2.59 \pm 10.16$ & $145.40 \pm 21.44$ & $-22.50 \pm 1.59$ & $-63.57 \pm 12.22$ \\
\hline CD01000 & $-201.98 \pm 15.30$ & $-35.31 \pm 9.28$ & $209.04 \pm 20.93$ & $-23.04 \pm 1.60$ & $-51.28 \pm 13.74$ \\
\hline
\end{tabular}

It is noteworthy that enoyl-acyl carrier protein reductases have been reported as attractive targets for the development of novel antibiotics. In one such study, the crystal structure of enoyl-ACP reductase (FabK) from Streptococcus pneumoniae in complex with phenylimidazole derivative inhibitor has been reported [53] (Figure 3). This implies that the enoyl reductase domain of FAS-I can be a promising target because it is crucial in the regulation of the pathway. The inhibitor has been reported to bind competitively with respect to NADH. The thiazole ring and a part of ureido moeity is involved in the $\pi-\pi$ stacking interaction with the isoalloxazine ring of the FMN molecule. Similarly, the active site of Mtb FAS-I consists of the tightly bound FMN molecule and the catalytic residue His584; hence, ligands containing aromatic rings possess potential for strong $\pi-\pi$ interactions with the FMN molecule. The presence of residues Thr436, His584, and Arg868 facilitates the formation of a hydrogen bond. Furthermore, the active site is large and open in nature, offering wide scope for optimization of compounds through additional groups. The proposed hit compounds can be pioneer inhibitors of Mtb FAS-I.

\section{Conclusions}

The key role of FAS-I in the survival and growth of mycobacterium makes it an attractive drug target. Only the pyrazinamide analogs have been reported as competitive inhibitors of FAS-I for NADPH binding. Therefore, in pursuit of finding potential inhibitors against FAS-I, we carried out structure-based virtual screening, focusing on the NADPH binding site of the enoyl reductase domain. Subsequently, molecular dynamics simulations were done to assess the stability of predicted binding poses and to perform MM/PBSAbased binding free energy. Based upon the predicted binding free energy values and stability of the compounds in the binding pocket, the compounds BTB14738, RH00608, SPB02705, and CD01000 have been proposed as putative hits. The calculated binding free energy indicates significant binding of the selected compounds. The proposed compounds can serve as pioneer inhibitors against Mtb FAS-I, which could pave the way for the development of a novel treatment for TB.

Supplementary Materials: The following are available online at https: / www.mdpi.com/article/ 10.3390/app11156977/s1, Figure S1: 2D interaction plots for selected protein-ligand complexes. Figure S2: The r.m.s.d plots shown for FMN molecule and protein backbone atoms.

Author Contributions: Conceptualization, W.L.; formal analysis, N.S.; investigation, N.S.; resources, W.L.; data curation, N.S.; writing-original draft preparation, N.S.; writing-review and editing, S.-Q.M. and W.L.; visualization, S.-Q.M.; supervision, W.L.; funding acquisition, W.L. All authors have read and agreed to the published version of the manuscript. 
Funding: This research was funded by Natural Science Foundation of Guangdong Province, China (Grant No. 2020A1515010984) and the Start-up Grant for Young Scientists (860-000002110384), Shenzhen University. The APC was funded by the Start-up Grant for Young Scientists (860-000002110384).

Institutional Review Board Statement: Not applicable.

Informed Consent Statement: Not applicable.

Data Availability Statement: The data presented in this study are available in the article and supplementary material.

Conflicts of Interest: The authors declare no conflict of interest.

\section{References}

1. WHO. Factsheet. 2019. Available online: https://www.who.int/tb/publications/factsheet_global.pdf?ua=1 (accessed on 22 October 2020).

2. WHO. News. 2019. Available online: https://www.who.int/news-room/fact-sheets/detail/tuberculosis (accessed on 20 October 2020).

3. Glickman, M.S.; Cox, J.S.; Jacobs, W.R. A Novel Mycolic Acid Cyclopropane Synthetase Is Required for Cording, Persistence, and Virulence of Mycobacterium tuberculosis. Mol. Cell 2000, 5, 717-727. [CrossRef]

4. Barkan, D.; Liu, Z.; Sacchettini, J.C.; Glickman, M.S. Mycolic Acid Cyclopropanation is Essential for Viability, Drug Resistance, and Cell Wall Integrity of Mycobacterium tuberculosis. Chem. Biol. 2009, 16, 499-509. [CrossRef] [PubMed]

5. Nataraj, V.; Varela, C.; Javid, A.; Singh, A.; Besra, G.S.; Bhatt, A. Mycolic acids: Deciphering and targeting the Achilles' heel of the tubercle bacillus. Mol. Microbiol. 2015, 98, 7-16. [CrossRef] [PubMed]

6. Takayama, K.; Wang, C.; Besra, G.S. Pathway to synthesis and processing of mycolic acids in Mycobacterium tuberculo-sis. Clin. Microbiol. Rev. 2005, 18, 81-101. [CrossRef] [PubMed]

7. Bhatt, A.; Molle, V.; Besra, G.S.; Jacobs, W.R., Jr.; Kremer, L. The Mycobacterium tuberculosis FAS-II condensing enzymes: Their role in mycolic acid biosynthesis, ac-id-fastness, pathogenesis and in future drug development. Mol. Microbiol. 2007, 64, 1442-1454. [CrossRef] [PubMed]

8. Brennan, J.P.; Nikaido, H. The envelope of mycobacteria. Annu. Rev. Biochem. 1995, 64, 29-63. [CrossRef] [PubMed]

9. Schweizer, E.; Hofmann, J. Microbial type I fatty acid synthases (FAS): Major players in a network of cellular FAS sys-tems. Microbiol. Mol. Biol. Rev. 2004, 68, 501-517. [CrossRef] [PubMed]

10. Lamichhane, G.; Zignol, M.; Blades, N.J.; Geiman, D.E.; Dougherty, A.; Grosset, J.; Broman, K.W.; Bishai, W.R. A postgenomic method for predicting essential genes at subsaturation levels of mutagenesis: Applica-tion to Mycobacterium tuberculosis. Proc. Natl. Acad. Sci. USA 2003, 100, 7213-7218. [CrossRef]

11. Sassetti, C.M.; Boyd, D.H.; Rubin, E.J. Comprehensive identification of conditionally essential genes in mycobacteria. Proc. Natl. Acad. Sci. USA 2001, 98, 12712-12717. [CrossRef]

12. Ma, Z.; Lienhardt, C.; McIlleron, H.; Nunn, A.; Wang, X. Global tuberculosis drug development pipeline: The need and the reality. Lancet 2010, 375, 2100-2109. [CrossRef]

13. Steele, M.A.; Prez, R.M.D. The Role of Pyrazinamide in Tuberculosis Chemotherapy. Chest 1988, 94, 845-850. [CrossRef]

14. Sayahi, H.; Pugliese, K.M.; Zimhony, O.; Jacobs, W.R.; Shekhtman, A.; Welch, J.T. Analogs of the Antituberculous Agent Pyrazinamide Are Competitive Inhibitors of NADPH Binding to M. tuberculosis Fatty Acid Synthase I. Chem. Biodivers. 2012, 9, 2582-2596. [CrossRef]

15. Zimhony, O.; Cox, J.S.; Welch, J.T.; Vilchèze, C.; Jacobs, W.R., Jr. Pyrazinamide inhibits the eukaryotic-like fatty acid synthetase I (FASI) of Mycobacterium tuberculosis. Nat. Med. 2000, 6, 1043-1047. [CrossRef]

16. Elad, N.; Baron, S.; Peleg, Y.; Albeck, S.; Grunwald, J.; Raviv, G.; Shakked, Z.; Zimhony, O.; Diskin, R. Structure of Type-I Mycobacterium tuberculosis fatty acid synthase at $3.3 \AA$ resolution. Nat. Commun. 2018, 9, 3886. [CrossRef]

17. Maia, E.H.B.; Assis, L.C.; De Oliveira, T.A.; Da Silva, A.M.; Taranto, A.G. Structure-Based Virtual Screening: From Classical to Artificial Intelligence. Front. Chem. 2020, 8, 343. [CrossRef] [PubMed]

18. Singh, N.; Tiwari, S.; Srivastava, K.K.; Siddiqi, M.I. Identification of Novel Inhibitors of Mycobacterium tuberculosis PknG Using Pharmacophore Based Virtual Screening, Docking, Molecular Dynamics Simulation, and Their Biological Evaluation. J. Chem. Inf. Model. 2015, 55, 1120-1129. [CrossRef] [PubMed]

19. Kumar, A.; Siddiqi, M.I.; Miertus, S. New molecular scaffolds for the design of Mycobacterium tuberculosis type II dehydroquinase inhibitors identified using ligand and receptor based virtual screening. J. Mol. Model. 2010, 16, 693-712. [CrossRef] [PubMed]

20. Vilar, S.; Sobarzo-Sanchez, E.; Santana, L.; Uriarte, E. Molecular Docking and Drug Discovery in $\beta$-Adrenergic Receptors. Curr. Med. Chem. 2017, 24, 4340-4359. [CrossRef] [PubMed]

21. Lionta, E.; Spyrou, G.; Vassilatis, D.K.; Cournia, Z. Structure-Based Virtual Screening for Drug Discovery: Principles, Applications and Recent Advances. Curr. Top. Med. Chem. 2014, 14, 1923-1938. [CrossRef] [PubMed]

22. Wang, T.; Wu, M.-B.; Chen, Z.-J.; Chen, H.; Lin, J.-P.; Yang, L.-R. Fragment-based drug discovery and molecular docking in drug design. Curr. Pharm. Biotechnol. 2015, 16, 11-25. [CrossRef] 
23. Moro, W.B.; Yang, Z.; Kane, T.A.; Brouillette, C.G.; Brouillette, W.J. Virtual screening to identify lead inhibitors for bacterial NAD synthetase (NADs). Bioorg. Med. Chem. Lett. 2009, 19, 2001-2005. [CrossRef]

24. Mishra, A.K.; Singh, N.; Agnihotri, P.; Mishra, S.; Singh, S.P.; Kolli, B.K.; Chang, K.P.; Sahasrabuddhe, A.A.; Siddiqi, M.I.; Pratap, J.V. Discovery of novel inhibitors for Leishmania nucleoside diphosphatase kinase (NDK) based on its struc-tural and functional characterization. J. Comput. Aided. Mol. Des. 2017, 31, 547-562. [CrossRef]

25. Lee, Y.-V.; Choi, S.B.; Wahab, H.A.; Lim, T.S.; Choong, Y.S. Applications of Ensemble Docking in Potential Inhibitor Screening forMycobacterium tuberculosisIsocitrate Lyase Using a Local Plant Database. J. Chem. Inf. Model. 2019, 59, 2487-2495. [CrossRef]

26. Kwofie, S.K.; Adobor, C.; Quansah, E.; Bentil, J.; Ampadu, M.; Miller, W.A.; Wilson, M.D. Molecular docking and dynamics simulations studies of OmpATb identifies four potential novel natural product-derived anti-Mycobacterium tuberculosis compounds. Comput. Biol. Med. 2020, 122, 103811. [CrossRef]

27. Zhao, W.; Xiong, M.; Yuan, X.; Li, M.; Sun, H.; Xu, Y. In Silico Screening-Based Discovery of Novel Inhibitors of Human Cyclic GMP-AMP Synthase: A Cross-Validation Study of Molecular Docking and Experimental Testing. J. Chem. Inf. Model. 2020, 60, 3265-3276. [CrossRef]

28. Newton, A.S.; Faver, J.C.; Micevic, G.; Muthusamy, V.; Kudalkar, S.N.; Bertoletti, N.; Anderson, K.S.; Bosenberg, M.W.; Jorgensen, W.L. Structure-Guided Identification of DNMT3B Inhibitors. ACS Med. Chem. Lett. 2020, 11, 971-976. [CrossRef] [PubMed]

29. Vázquez-Jiménez, L.K.; Paz-González, A.D.; Juárez-Saldivar, A.; Uhrig, M.L.; Agusti, R.; Reyes-Arellano, A.; Nogueda-Torres, B.; Rivera, G. Structure-Based Virtual Screening of New Benzoic Acid Derivatives as Trypanosoma cruzi Trans-sialidase Inhibitors. Med. Chem. 2020, 16, 1-9. [CrossRef]

30. Gupta, D.; Singh, A.; Somvanshi, P.; Singh, A.; Khan, A.U. Structure-Based Screening of Non- $\beta$-Lactam Inhibitors against Class D $\beta$-Lactamases: An Approach of Docking and Molecular Dynamics. ACS Omega 2020, 5, 9356-9365. [CrossRef] [PubMed]

31. Poli, G.; Granchi, C.; Rizzolio, F.; Tuccinardi, T. Application of MM-PBSA Methods in Virtual Screening. Molecules 2020, $25,1971$. [CrossRef] [PubMed]

32. Maybridge Library. Available online: http:/ / www.maybridge.com/ (accessed on 25 December 2020).

33. Jain, A.N. Surflex: Fully Automatic Flexible Molecular Docking Using a Molecular Similarity-Based Search Engine. J. Med. Chem. 2003, 46, 499-511. [CrossRef] [PubMed]

34. Berendsen, H.J.; van der Spoel, D.; van Drunen, R. GROMACS-A message-passing parallel molecu-lar-dynamics implementation. Comput. Phys. Commun. 1995, 91, 43-56. [CrossRef]

35. Vanommeslaeghe, K.; Hatcher, E.; Acharya, C.; Kundu, S.; Zhong, S.; Shim, J.; Darian, E.; Guvench, O.; Lopes, P.E.M.; Vorobyov, I.; et al. CHARMM general force field: A force field for drug-like molecules compatible with the CHARMM all-atom additive biological force fields. J. Comput. Chem. 2009, 31, 671-690. [CrossRef] [PubMed]

36. Vanommeslaeghe, K.; Raman, E.P.; MacKerell, A.D. Automation of the CHARMM General Force Field (CGenFF) II: As-signment of bonded parameters and partial atomic charges. J. Chem. Inf. Model. 2012, 52, 3155-3168. [CrossRef]

37. Darden, T.; York, D.; Pedersen, L. Particle mesh Ewald: An N. $\log (\mathrm{N})$ method for Ewald sums in large systems. J. Chem. Phys. 1993, 98, 10089-10092. [CrossRef]

38. Available online: http://plasma-gate.weizmann.ac.il/Grace/ (accessed on 12 April 2020).

39. Hou, T.; Wang, J.; Li, Y.; Wang, W. Assessing the performance of the molecular mechanics/Poisson Boltzmann surface area and molecular me-chanics/generalized Born surface area methods. II. The accuracy of ranking poses generated from docking. J. Comput. Chem. 2011, 32, 866-877. [CrossRef]

40. Kumari, R.; Kumar, R.; Open Source Drug Discovery Consortium; Lynn, A. g_mmpbsa-A GROMACS tool for high-throughput MM/PBSA calculations. J. Chem. Inf. Model. 2014, 54, 1951-1962. [CrossRef] [PubMed]

41. Wright, D.; Hall, B.A.; Kenway, O.A.; Jha, S.; Coveney, P.V. Computing Clinically Relevant Binding Free Energies of HIV-1 Protease Inhibitors. J. Chem. Theory Comput. 2014, 10, 1228-1241. [CrossRef]

42. Xu, L.; Sun, H.; Li, Y.; Wang, J.; Hou, T. Assessing the Performance of MM/PBSA and MM/GBSA Methods. The Impact of Force Fields and Ligand Charge Models. J. Phys. Chem. B 2013, 117, 8408-8421. [CrossRef]

43. Homeyer, N.; Gohlke, H. Free Energy Calculations by the Molecular Mechanics Poisson-Boltzmann Surface Area Method. Mol. Inform. 2012, 31, 114-122. [CrossRef]

44. Baker, N.A.; Sept, D.; Joseph, S.; Holst, M.J.; McCammon, J.A. Electrostatics of nanosystems: Application to microtubules and the ribosome. Proc. Natl. Acad. Sci. USA 2001, 98, 10037-10041. [CrossRef]

45. Levy, R.M.; Zhang, L.Y.; Gallicchio, E.; Felts, A.K. On the nonpolar hydration free energy of proteins: Surface area and continuum solvent models for the so-lute-solvent interaction energy. J. Am. Chem. Soc. 2003, 125, 9523-9530. [CrossRef]

46. Tan, C.; Tan, Y.-H.; Luo, R. Implicit Nonpolar Solvent Models. J. Phys. Chem. B 2007, 111, 12263-12274. [CrossRef]

47. Jenni, S.; Leibundgut, M.; Boehringer, D.; Frick, C.; Mikolásek, B.; Ban, N. Structure of Fungal Fatty Acid Synthase and Implications for Iterative Substrate Shuttling. Science 2007, 316, 254-261. [CrossRef] [PubMed]

48. Wang, E.; Sun, H.; Wang, J.; Wang, Z.; Liu, H.; Zhang, J.Z.; Hou, T. End-Point Binding Free Energy Calculation with MM/PBSA and MM/GBSA: Strategies and Applications in Drug Design. Chem. Rev. 2019, 119, 9478-9508. [CrossRef]

49. Botelho, F.D.; Gonçalves, A.S.; França, T.C.; LaPlante, S.R.; de Almeida, J.S. Identification of novel potential ricin inhibitors by virtual screening, molecular docking, molecular dy-namics and MM/PBSA calculations: A drug repurposing approach. J. Biomol. Struct. Dyn. 2021. [CrossRef] 
50. Genheden, S.; Ryde, U. The MM/PBSA and MM/GBSA methods to estimate ligand-binding affinities. Expert Opin. Drug Discov. 2015, 10, 449-461. [CrossRef] [PubMed]

51. Laurini, E.; Col, V.D.; Mamolo, M.G.; Zampieri, D.; Posocco, P.; Fermeglia, M.; Vio, L.; Pricl, S. Homology Model and DockingBased Virtual Screening for Ligands of the $\sigma 1$ Receptor. ACS Med. Chem. Lett. 2011, 2, 834-839. [CrossRef] [PubMed]

52. Venken, T.; Krnavek, D.; Münch, J.; Kirchhoff, F.; Henklein, P.; De Maeyer, M.; Voet, A. An optimized MM/PBSA virtual screening approach applied to an HIV-1 gp41 fusion peptide inhibitor. Proteins Struct. Funct. Bioinform. 2011, 79, 3221-3235. [CrossRef]

53. Saito, J.; Yamada, M.; Watanabe, T.; Iida, M.; Kitagawa, H.; Takahata, S.; Ozawa, T.; Takeuchi, Y.; Ohsawa, F. Crystal structure of enoyl-acyl carrier protein reductase (FabK) from Streptococcus pneumoniae reveals the binding mode of an inhibitor. Protein. Sci. 2008, 17, 691-699. [CrossRef] 